\title{
Research on the cost effectiveness of carbon emission reduction in the full life cycle of electric vehicles based on grey prediction
}

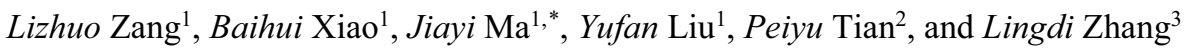 \\ ${ }^{1}$ College of Automotive Engineering, Jilin University, Changchun 130000, China \\ ${ }^{2}$ College of Computer Science and Technology, Jilin University, Changchun 130000, China \\ ${ }^{3}$ Shandong Weifang Haotai Machinery Co., Ltd., China
}

\begin{abstract}
In order to research the carbon emission reduction potential of electric vehicles, a cost effectiveness model is used to calculate and compare the economic costs and carbon emissions of fuel vehicles and electric vehicles throughout the life cycle, and an improved grey prediction model is utilized to analyze the future trends of electric vehicle emission reduction benefits. The results show that electric vehicles play a positive role in carbon emission reduction, and the unit cost of carbon emission reduction is decreasing by years. Therefore, China should vigorously develop the electric vehicle industry and technology, and achieve the strategic goal of carbon emission reduction by promoting the electrification of vehicles.
\end{abstract}

Keywords: Electric vehicle, Carbon emission reduction, Cost effectiveness, Full life cycle, Grey prediction.

\section{Introduction}

With the globalization of climate warming, China has included "carbon peak" and "carbon neutrality" in its national strategy. As one of the current main sources of carbon emissions, automobiles have a huge impact on environmental issues. Therefore, controlling automobile carbon emissions is of great significance to the energy conservation and emission reduction of the entire transportation industry ${ }^{[1]}$. Many experts and scholars believe that the development of electric vehicles is a positive means of reducing emissions. Zhao Fuquan et al. ${ }^{[2]}$ analyzed the influencing factors of the low-carbon development of the automobile industry and believed that electric vehicles have great advantages in replacing traditional fuel vehicles and promoting carbon emission reduction in the transportation sector. Zhao Zixian et al. ${ }^{[3]}$ used the life cycle assessment method to calculate the carbon emission reduction effect of private electric vehicles relative to traditional fuel vehicles. Compared with traditional fuel vehicles, private electric vehicles have a better carbon emission reduction effect in the 13 provinces with a low proportion of thermal power generation. Gao Yinqiao ${ }^{[4]}$ used the vehicle fuel life cycle method to analyze battery

\footnotetext{
*Corresponding author: majiayi@j]lu.edu.cn
} 
electric vehicles, hybrid vehicles, and fuel vehicles. It is found that battery electric vehicles have the best carbon emission reduction effect. Kong Weizheng et al. ${ }^{[5]}$ calculated the changes in energy consumption, $\mathrm{CO}_{2}$ and other greenhouse gases and other pollutants emissions from the perspective of full-cycle energy efficiency. If fuel vehicles are replaced by electric vehicles, $\mathrm{CO}_{2}$ and other greenhouse gas emissions will decrease. Sun Hanjie ${ }^{[6]}$ applied the full life cycle analysis method to establish the carbon emission calculation model of electric vehicles, and compared it with traditional fuel vehicles. The results showed that under Chinese current power generation ratio, the carbon emissions during the use of electric vehicles are reduced by about $10 \%$ compared with fuel vehicles. While considering the carbon emission reduction effect of electric vehicles, how to reduce the emission reduction cost and improve the cost effectiveness is also the focus of current attention. Qi Xingda et al. ${ }^{[7]}$ analyzed the greenhouse gas emission reduction cost effectiveness of battery electric vehicles relative to traditional fuel vehicles based on the full life cycle of vehicles, and concluded that electric vehicles have the effect of reducing greenhouse gas emissions. But the research process only takes a few models as examples, and it is limited to a certain point in time, without analyzing and predicting the future. At present, however, electric vehicle industry is developing rapidly, and the technology of electric vehicles is changing with each passing day. As a result, previous researches like this have limited reference for the current automobile industry.

Therefore, this paper starts from the perspective of the cost effectiveness of carbon emission reduction throughout the life cycle, and compares the data of 120 fuel vehicles and electric vehicles in total; Then, the gray prediction algorithm is used to research the carbon emission reduction of electric vehicles ${ }^{[8]}$; Finally, according to the change trend of the emission reduction benefits from 2016 to 2025, a comprehensive assessment is conducted of the electric vehicles emission reduction potential, so as to put forward suggestions for improving the emission reduction benefits of electric vehicles.

\section{Emission reduction benefit analysis based on cost effectiveness}

\subsection{The cost effectiveness model of carbon emission reduction}

In order to measure the comprehensive benefits of carbon emission reduction, battery electric vehicles can be compared with traditional fuel vehicles, and a carbon emission reduction cost effectiveness model can be established. In this model, the unit cost of carbon emission reduction is used to measure the effectiveness of carbon emission reduction costs. And the lower the unit cost is, the better the cost effectiveness is. The specific calculation process of the unit cost is shown in formula (1):

$$
\mathrm{U}=\frac{\mathrm{C}_{t}}{E_{t}}=\frac{\left(C_{e}-C_{f}\right)}{\left(E_{f}-E_{e}\right)}
$$

Among them, $\mathrm{U}$ is the unit cost of carbon emission reduction, whose unit is yuan $/ \mathrm{kgCO}_{2}$; $\mathrm{C}_{\mathrm{t}}$ is the economic cost of carbon emission reduction, whose unit is yuan; $\mathrm{E}_{\mathrm{t}}$ is the carbon emission reduction amount, whose unit is $\mathrm{kgCO}_{2} ; \mathrm{C}_{\mathrm{e}}$ is the full life cycle economic cost of battery electric vehicles, whose unit is yuan; $\mathrm{C}_{\mathrm{f}}$ is the full life cycle economic cost of fuel vehicles, whose unit is yuan; $\mathrm{E}_{\mathrm{f}}$ is the full life cycle carbon emissions of fuel vehicles, whose unit is $\mathrm{kgCO}_{2} ; \mathrm{E}_{\mathrm{e}}$ is the full life cycle carbon emissions of battery electric vehicles, whose unit is $\mathrm{kgCO}_{2}$.

Based on the accuracy and feasibility of the data, this paper selects 60 traditional fuel vehicles and 60 corresponding battery electric vehicles presented in 2016-2021 as samples 
for research to ensure that the selected vehicles are mainly different in the form of the power system rather than other aspects. At the same time, assuming that the average full life cycle of all vehicles is 150,000 kilometers in 12 years, the full life cycle economic cost and the full life cycle carbon emissions are calculated on this premise.

\subsubsection{Full life cycle economic cost}

In terms of the economic cost of the full life cycle, comprehensive analysis can be made from the aspects of car purchase price, purchase tax, vehicle and vessel tax, compulsory traffic insurance, commercial insurance, license fee, fuel cost, maintenance fee, car residual value, etc., to construct a full life cycle economic cost indicator system, as shown in Table 1:

Table 1. Full life cycle economic costs.

\begin{tabular}{|c|c|c|}
\hline Economic cost indicator & Traditional fuel car & Battery electric vehicle \\
\hline Purchase price (yuan) & $\begin{array}{l}\text { Calculate according to the average } \\
\text { value of the new car guide price of the } \\
\text { selected annual vehicle models }\end{array}$ & $\begin{array}{l}\text { Calculate according to the } \\
\text { average value of the new car } \\
\text { guide price of the selected } \\
\text { annual vehicle models }\end{array}$ \\
\hline Purchase tax (yuan) & $\begin{array}{l}\text { Set the } 1.6 \mathrm{~T} \text { vehicle with an average } \\
\text { level of } 150,000 \text { fuel vehicles, } \\
\text { calculated according to the } \\
\text { corresponding annual policies }\end{array}$ & Tax exempt, recorded as 0 \\
\hline $\begin{array}{l}\text { Vehicle and vessel tax } \\
\text { (yuan) }\end{array}$ & $\begin{array}{l}\text { Set a } 1.6 \mathrm{~T} \text { vehicle with an average } \\
\text { level of } 150,000 \text { fuel vehicles. } \\
\text { According to the average level of local } \\
\text { policies, take } 360 \text { yuan/year } \times 12 \\
\text { years }=4320 \text { yuan }\end{array}$ & Tax exempt, recorded as 0 \\
\hline $\begin{array}{l}\text { Compulsory traffic } \\
\text { insurance (yuan) }\end{array}$ & same & \\
\hline $\begin{array}{l}\text { Commercial insurance } \\
\text { (yuan) }\end{array}$ & \multicolumn{2}{|c|}{ The actual difference is limited, assuming the same } \\
\hline License fee (yuan) & same & \\
\hline Fuel cost (yuan) & $\begin{array}{l}\text { Calculate according to the average } \\
\text { fuel consumption of the selected } \\
\text { annual vehicle models, and assume } \\
\text { that the average gasoline price is } 6.8 \\
\text { yuan/L }\end{array}$ & $\begin{array}{l}\text { Calculate according to the } \\
\text { average power consumption } \\
\text { of the selected annual vehicle } \\
\text { models, and assume that the } \\
\text { average charging cost of } \\
\text { electric vehicles is } 1.2 \text { yuan } / \mathrm{L}\end{array}$ \\
\hline Maintenance fee (yuan) & $\begin{array}{l}\text { Calculated according to the average } \\
\text { annual maintenance cost of } 2,000 \text { yuan }\end{array}$ & $\begin{array}{l}\text { Calculated according to the } \\
\text { average annual maintenance } \\
\text { cost of } 500 \text { yuan }\end{array}$ \\
\hline Car residual value (yuan) & \multicolumn{2}{|c|}{$\begin{array}{l}\text { Assumptions are used until they are scrapped, and the residual value is } \\
\text { zero }\end{array}$} \\
\hline
\end{tabular}

Taking into account the availability of data, this paper uses the purchase price to represent the comprehensive economic cost of the car in the production stage, and the rest of the indicators to represent the economic cost of the car in the use stage.

Since the purchase tax is greatly affected by the policy, it needs to be calculated in accordance with the formula. Assuming that the purchase tax is $T_{\mathrm{P}}$, the purchase price is $\mathrm{P}_{\mathrm{V}}$, the value-added tax rate is $R_{V A T}$, and the purchase tax rate is $R_{\mathrm{PT}}$, the purchase tax calculation formula is: 


$$
T_{p}=\frac{P_{v}}{\left(1+R_{V A T}\right)} \times R_{P T}
$$

Assuming that the annual average purchase price of traditional fuel vehicles is 150,000 yuan per vehicle, and the calculation is carried out according to formula (2), the calculation results are shown in Table 2:

Table 2. Calculation of vehicle purchase tax.

\begin{tabular}{cccc}
\hline Year & $\begin{array}{c}\text { Value-added tax } \\
\text { rate }\end{array}$ & Purchase tax rate & Purchase tax (yuan) \\
\hline 2016 & $17 \%$ & $5 \%$ (Preferential policy) & 6410.26 \\
2017 & $17 \%$ & $7.5 \%$ (Preferential policy) & 9615.38 \\
2018 & $16 \%$ & $10 \%$ & 12931.03 \\
2019 & $13 \%$ & $10 \%$ & 13274.34 \\
2020 & $13 \%$ & $10 \%$ & 13274.34 \\
2021 & $13 \%$ & $10 \%$ & 13274.34 \\
\hline
\end{tabular}

Fuel costs should be considered separately from the two aspects of fuel vehicles and electric vehicles. In terms of fuel vehicles, on the one hand, in order to avoid the impact of uncertain factors such as fuel price fluctuations on the economic cost of fuel vehicles throughout the life cycle, the average price of 92 gasoline and 95 gasoline in the past five years is selected to estimate proportionally. So the price of gasoline is set at 6.8 yuan per liter. On the other hand, in order to ensure the authenticity and objectivity of the fuel consumption data, the average NEDC fuel consumption of the selected annual vehicle models in the sample is multiplied by the amplification factor 1.15 to obtain the actual fuel consumption per 100 kilometers. Assuming that the fuel cost of a fuel vehicle is M (yuan) and the actual average fuel consumption is $\mathrm{F}(\mathrm{L} / 100 \mathrm{~km})$, then:

$$
M=F \times 1500 \times 6.8
$$

In terms of electric vehicles, the construction of infrastructures such as charging piles needs to be strengthened to meet the growing demand for charging. Therefore, when calculating the fuel consumption of electric vehicles, it is not only necessary to consider the price of electricity itself, but also the cost of infrastructure construction. Since the charging price of public charging piles already covers the cost of infrastructure construction, the average charging price of public charging piles can be selected to calculate the fuel cost of electric vehicles, which is 1.2 yuan $/ \mathrm{kWh}$. At the same time, the average NEDC power consumption of the selected annual vehicle models in the sample should be multiplied by the amplification factor 1.15 to get the actual power consumption per 100 kilometers. Assuming that the full life cycle fuel cost of an electric vehicle is $\mathrm{N}$ (yuan), and the actual average power consumption is $\mathrm{G}(\mathrm{L} / 100 \mathrm{~km})$, then:

$$
N=G \times 1500 \times 1.2
$$

Calculate according to formula (3) and formula (4), and the specific values of fuel cost are shown in Table 3 below:

Table 3. Calculation of vehicle fuel cost.

\begin{tabular}{lllll}
\hline Year & $\begin{array}{c}\text { Actual average } \\
\text { fuel consumption } \\
(\mathbf{L} / \mathbf{1 0 0} \mathbf{k m})\end{array}$ & $\begin{array}{c}\text { Actual average } \\
\text { power } \\
\text { consumption } \\
\mathbf{( k W h / 1 0 0 k m )}\end{array}$ & $\begin{array}{c}\text { Full life cycle fuel } \\
\text { cost of fuel } \\
\text { vehicles (yuan) }\end{array}$ & $\begin{array}{c}\text { Full life cycle fuel } \\
\text { cost of electric } \\
\text { vehicles (yuan) }\end{array}$ \\
\hline 2016 & 7.892 & 16.764 & 80498.4 & 30175.2 \\
2017 & 7.866 & 16.434 & 80233.2 & 29581.2 \\
\hline
\end{tabular}




\begin{tabular}{lllll}
\hline 2018 & 7.786 & 15.928 & 79417.2 & 28670.4 \\
2019 & 7.653 & 15.304 & 78060.6 & 27547.2 \\
2020 & 7.648 & 14.984 & 78009.6 & 26971.2 \\
2021 & 7.621 & 14.762 & 77734.2 & 26571.6 \\
\hline
\end{tabular}

Finally, the economic costs are comprehensively calculated, using the full life cycle costs of battery electric vehicles to subtract that of fuel vehicles to obtain the cost difference, which is the economic cost of carbon emission reduction $C_{t}$, as shown in Table 4:

Table 4. Economic cost of carbon emission reduction.

\begin{tabular}{cc}
\hline Year & Economic cost of carbon emission reduction (yuan) \\
\hline 2016 & 110407 \\
2017 & 52573 \\
2018 & 26562 \\
2019 & 13852 \\
2020 & 7027 \\
2021 & 3603 \\
\hline
\end{tabular}

\subsubsection{Full life cycle carbon emissions}

For the full life cycle of a vehicle, its carbon emissions can be considered mainly from the three stages of production, use, and scrapping. Since the carbon emissions of discarded batteries can be reduced to a large extent after proper treatment, the carbon emissions gap between battery electric vehicles and fuel vehicles can be mainly manifested in the production and use stages.

Table 5. Carbon emissions during vehicle production stage.

\begin{tabular}{|c|c|c|}
\hline Year & $\begin{array}{c}\text { Carbon emissions during the } \\
\text { production stage of traditional } \\
\text { fuel vehicles }\left(\mathrm{kgCO}_{2}\right)\end{array}$ & $\begin{array}{l}\text { Carbon emissions during the } \\
\text { production stage of battery } \\
\text { electric vehicles }\left(\mathrm{kgCO}_{2}\right) \\
\end{array}$ \\
\hline 2016 & 8700 & 11500 \\
\hline 2017 & 8590 & 11530 \\
\hline 2018 & 8520 & 11670 \\
\hline 2019 & 8430 & 11750 \\
\hline 2020 & 8350 & 11900 \\
\hline 2021 & 8280 & 12080 \\
\hline
\end{tabular}

In the production stage, the statistical data of each year in the sample will be averaged, as shown in Table 5. The table shows that with the optimization and upgrading of manufacturing technology, the carbon emissions of traditional fuel vehicles in the production stage will drop slightly. And with the increase in the mileage requirements of electric vehicles, it is inevitable to increase the battery pack capacity. Although the level of production technology is constantly improving, it still cannot fully offset the increase of carbon emissions caused by larger battery packs.

In the use stage, the calculation of carbon emissions needs to be considered separately from the perspective of gasoline and electricity. Assuming that the carbon emissions during the use stage of a traditional fuel vehicle is $\mathrm{E}_{\mathrm{UF}}\left(\mathrm{kgCO}_{2}\right)$, the actual average fuel consumption is $\mathrm{F}(\mathrm{L} / 100 \mathrm{~km})$, and the gasoline carbon emission coefficient is $\mathrm{K}_{\mathrm{F}}\left(\mathrm{kgCO}_{2} / \mathrm{L}\right)$, then the carbon emissions during the use stage can be calculated according to the formula (5):

$$
E_{U F}=F \times K_{F} \times 1500
$$


According to relevant authoritative data, $\mathrm{K}_{\mathrm{F}}$ is taken as $2.1353 \mathrm{kgCO}_{2} / \mathrm{L}$, and the calculation results are shown in Table 6:

Table 6. Carbon emissions during the use stage of fuel vehicles.

\begin{tabular}{ccc}
\hline Year & $\begin{array}{c}\text { Actual average fuel } \\
\text { consumption } \\
\text { (L/100km) }\end{array}$ & $\begin{array}{c}\text { Carbon emissions during the use } \\
\text { stage of traditional fuel vehicles } \\
\text { (kgCO2) }\end{array}$ \\
\hline 2016 & 7.892 & 25277.68 \\
2017 & 7.866 & 25194.40 \\
2018 & 7.786 & 24938.17 \\
2019 & 7.653 & 24512.18 \\
2020 & 7.648 & 24496.16 \\
2021 & 7.621 & 24409.68 \\
\hline
\end{tabular}

For battery electric vehicles, the carbon emissions during the use stage are mainly due to the indirect carbon emissions from the power generation of power plants. Among the current forms of power generation, carbon emissions are mainly derived from thermal power generation, so the annual coal consumption rate can be used to calculate the carbon emission coefficient of electricity. Assuming that the carbon emission coefficient of electricity is $\mathrm{K}_{\mathrm{E}}\left(\mathrm{kgCO}_{2} / \mathrm{kWh}\right)$, the coal consumption rate is $\mathrm{R}_{\mathrm{co}}(\mathrm{gCO} / \mathrm{kWh})$, and the standard coal carbon emission factor is $\mathrm{F}_{\mathrm{co}}\left(\mathrm{kgCO}_{2} / \mathrm{kgCO}\right)$, the calculation formula is:

$$
K_{E}=R_{C O} \times F_{C O} \times 0.001
$$

Then, assuming that the carbon emission during the use stage of a battery electric vehicle is $E_{U E}$ and the actual average power consumption is $\mathrm{G}(\mathrm{kWh} / 100 \mathrm{~km})$, the carbon emissions during the use stage of battery electric vehicles can be calculated according to formula (7):

$$
E_{U E}=G \times K_{E} \times 1500=G \times R_{C O} \times F_{C O} \times 1.5
$$

It is known that standard coal emission factor is $2.716 \mathrm{kgCO}_{2} / \mathrm{kgCO}$. According to statistical data, the calculation results are shown in Table 7:

Table 7. Carbon emissions during the use stage of electric vehicles.

\begin{tabular}{cccc}
\hline Year & $\begin{array}{c}\text { Actual average power } \\
\text { consumption } \\
\mathbf{( k W h / 1 0 0 k m )}\end{array}$ & $\begin{array}{c}\text { Coal consumption } \\
\text { rate }(\mathbf{g C O} / \mathbf{k W h})\end{array}$ & $\begin{array}{c}\text { Carbon emissions during the use } \\
\text { stage of battery electric vehicles } \\
\text { (kgCO2) }\end{array}$ \\
\hline 2016 & 16.764 & 312 & 21310.87 \\
2017 & 16.434 & 309 & 20690.49 \\
2018 & 15.928 & 308 & 19988.53 \\
2019 & 15.304 & 307 & 19143.10 \\
2020 & 14.984 & 305.5 & 18651.25 \\
2021 & 14.762 & 301.4 & 18128.32 \\
\hline
\end{tabular}

Finally, the full life cycle carbon emissions of traditional fuel vehicles and battery electric vehicles are comprehensively calculated and compared, so as to obtain the carbon emission reduction $E_{t}$ of the vehicles over the years, as shown in Table 8:

Table 8. Carbon emission reduction.

\begin{tabular}{lc}
\hline Year & Carbon emission reduction $\left(\mathbf{k g C O}_{2}\right)$ \\
\hline 2016 & 1166.81 \\
2017 & 1563.92 \\
2018 & 1799.63 \\
\hline
\end{tabular}




\begin{tabular}{ll}
\hline 2019 & 2049.07 \\
2020 & 2294.91 \\
2021 & 2481.37 \\
\hline
\end{tabular}

\section{Grey prediction}

\subsection{Grey prediction algorithm}

Grey theory is an important means to research grey systems, and grey prediction algorithm is the core part of grey theory ${ }^{[9]}$. This method takes into account that the evolution of a system is affected by many uncertain factors, and can solve the problems of less historical data, sequence integrity and low reliability. In addition, in order to improve the accuracy of the prediction results, this paper slightly improves the gray prediction model in the process of data preprocessing. And the main process of the improved gray prediction model is shown in Figure 1.

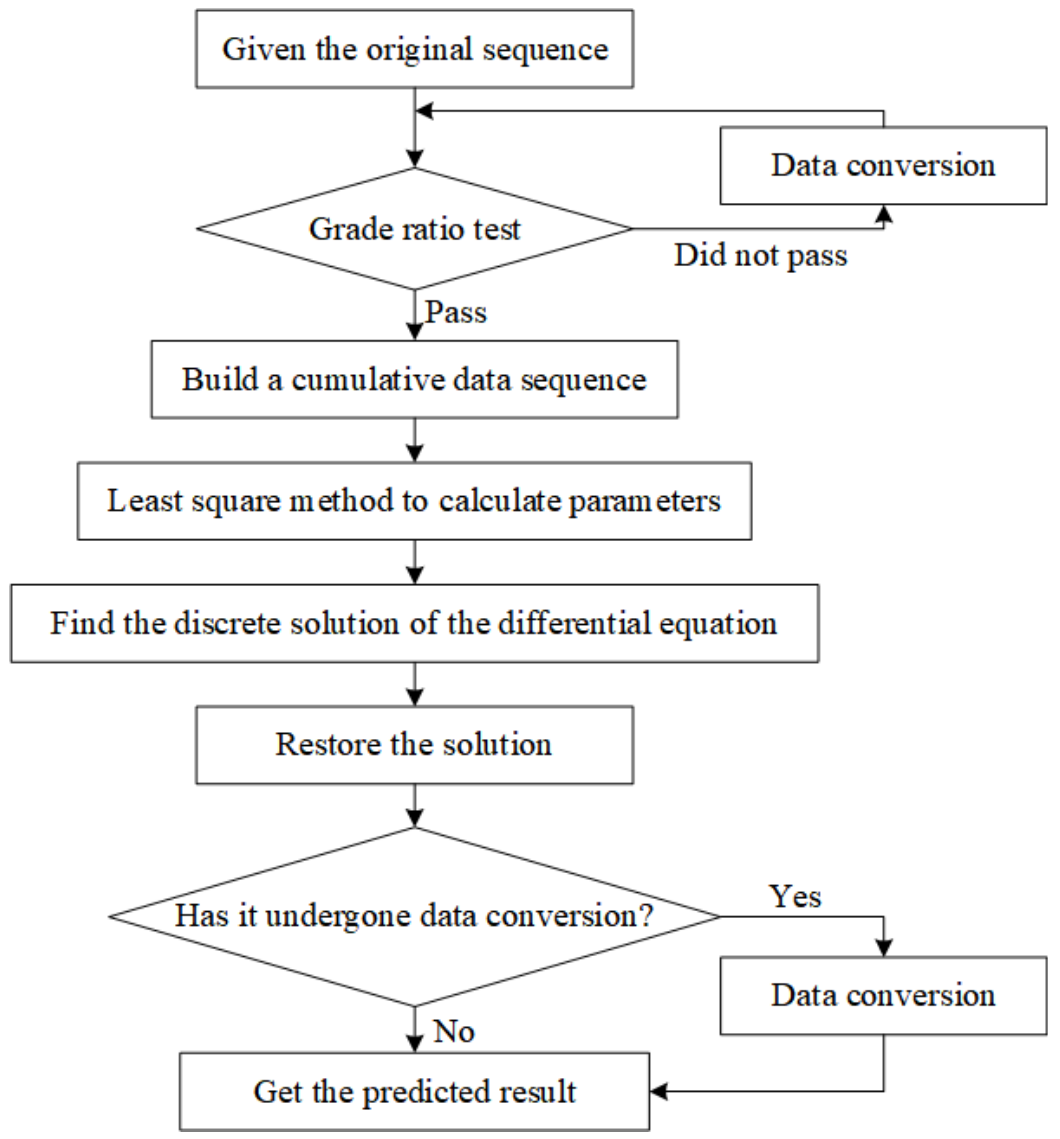

Fig. 1. Flow chart of grey prediction algorithm.

\subsection{Data preprocessing}

Based on the data related to electric vehicles from 2016 to 2021, the original sequence of carbon emission reduction and the economic cost can be expressed respectively as: 


$$
\begin{aligned}
& \mathrm{y}^{(0)}=\left\{\mathrm{y}^{(0)}(1), \mathrm{y}^{(0)}(2), \cdots, y^{(0)}(6)\right\}=\{1166.81,1563.92,1799.63,2049.07,2294.91,2481.37\} \\
& z^{(0)}=\left\{z^{(0)}(1), z^{(0)}(2), \cdots, z^{(0)}(6)\right\}=\{110406,52572.62,26562.17,13852.26,7027.26,3603.06\}
\end{aligned}
$$

Due to the large volatility of the original data, a grade ratio test is performed on the known data sequence, in order to ensure the feasibility of the modeling method:

$$
\begin{array}{r}
\lambda_{\mathrm{y}}(k)=\frac{\mathrm{y}^{(0)}(k-1)}{y^{(0)}(k)}, k=2,3, \cdots, 6 \\
\lambda_{z}(k)=\frac{z^{(0)}(k-1)}{z^{(0)}(k)}, k=2,3, \cdots, 6
\end{array}
$$

After the grade ratio test, the results are $\lambda_{\mathrm{y}}(k), \lambda_{z}(k)$, as shown in the following table:

Table 9. Grade ratio.

\begin{tabular}{lll}
\hline $\mathbf{k}$ & $\lambda_{y}(k)$ & $\lambda_{z}(k)$ \\
\hline 2 & 0.746080362 & 2.100076808 \\
3 & 0.869023077 & 1.979229107 \\
4 & 0.878266726 & 1.917533312 \\
5 & 0.892875973 & 1.9712178 \\
6 & 0.924856027 & 1.950358862 \\
\hline
\end{tabular}

By judging if all the grade ratios $\lambda(k)$ fall into the acceptable coverage, it can be determined whether the original sequence can be used as the data of the model $\operatorname{GM}(1,1)$ for grey prediction. If the data sequence have not passed the grade ratio test, the data can be converted to reduce its volatility, thereby meeting the requirements. The main calculation process is as follows:

$$
\begin{gathered}
y_{1}^{(0)}(k)=y^{(0)}(k)+c_{1} \\
z_{1}^{(0)}(k)=\ln \left(z^{(0)}(k)\right) \\
z_{2}^{(0)}(k)=z_{1}^{(0)}(k)+c_{2}
\end{gathered}
$$

After performing conversion operation on the original sequence, the results can be expressed as new sequences:

$$
y_{1}^{(0)}=\left\{y_{1}^{(0)}(1), y_{1}^{(0)}(2), \cdots, y_{1}^{(0)}(6)\right\}, z_{1}^{(0)}=\left\{z_{1}^{(0)}(1), z_{1}^{(0)}(2), \cdots, z_{1}^{(0)}(6)\right\} .
$$

When predicting the economic cost of carbon emission reduction, according to the data situation, it can be known that the index sequence ${ }^{[8]} z^{(0)}(k)=b e^{-a t}$ is the best form of data fitting, with the development coefficient $a$ and the coordination coefficient $b$. In order to overcome the defect of missing the first point in the traditional $\operatorname{GM}(1,1)$ model, a value can be added before the data sequence to ensure that all points can participate in the prediction process. So the data sequence is transformed into:

$$
z_{3}^{(0)}=\left\{g, z_{3}^{(0)}(1), z_{3}^{(0)}(2), \cdots, z_{3}^{(0)}(N)\right\}
$$

And

$$
z_{3}^{(0)}(1)=z_{2}^{(0)}(1), z_{3}^{(0)}(2)=z_{2}^{(0)}(2), \cdots, z_{3}^{(0)}(N)=z_{2}^{(0)}(N)
$$


Substitute $k=0$ and find $g=z^{(0)}(0)=b e^{-a \cdot 0}=b$. In this way, a $z_{3}^{(0)}$ prediction data sequence is obtained.

\subsection{Calculation process}

The following content uses carbon emission reduction as an example to illustrate the calculation process of gray prediction.

First, let $\quad y^{(1)}(k)=\sum_{i=1}^{k} y^{(0)}(i), k=1,2,3, \cdots, N \quad, \quad$ then $\mathrm{y}^{(1)}=\left\{\mathrm{y}^{(1)}(1), \mathrm{y}^{(1)}(2), \cdots, y^{(1)}(6)\right\}$ is a new cumulative data sequence. The differential equation of the grey prediction model is:

$$
\frac{d(y)^{(1)}}{d t}+q y^{(1)}=d
$$

$q$ is the development coefficient of the model, and $d$ is the coordination coefficient of the model. Then according to the least square method, the values of $q$ and $d$ can be calculated and substituted into the differential equation.

Then the discrete solution of the differential equation is:

$$
\hat{y}^{(1)}(k+1)=\left(y^{(0)}(1)-\frac{d}{q}\right) e^{-q k}+\frac{d}{q}, k=1,2,3, \cdots, n
$$

If given an initial condition: $\hat{y}^{(0)}(1)=y^{(1)}(1)=y^{(0)}(1)$, the data sequence is restored to

$$
\hat{y}^{(0)}(k+1)=\hat{y}^{(1)}(k+1)-\hat{y}^{(1)}(k)=\left(1-e^{q}\right)\left(y^{(0)}(1)-\frac{d}{q}\right) e^{-q k}, k=1,2,3, \cdots, n
$$

Then restore the conversion process to get

$$
y_{2}^{(0)}(k)=\hat{y}^{(0)}(k)-c_{1}
$$

For the economic cost of carbon emission reduction, the previous calculation process is the same as the above process. But after that, the data which has been taken out of the logarithm needs to be exponentially restored, in order to obtain the predicted economic cost of carbon emission reduction, as shown in the following formula :

$$
z_{4}^{(0)}(k)=\exp \left(z_{3}^{(0)}(k)\right)
$$

\subsection{Calculation results and analysis}

After bringing the data into the grey prediction model, this paper calculate the carbon emission reduction amount and the economic cost of carbon emission reduction from 2022 to 2025 , as shown in the following table: 
Table 10. Gray prediction data results.

\begin{tabular}{ccc}
\hline Year & $\begin{array}{c}\text { Carbon emission } \\
\text { reduction (kgCO2) }\end{array}$ & $\begin{array}{c}\text { Economic cost of carbon emission } \\
\text { reduction (yuan) }\end{array}$ \\
\hline 2022 & 2736.91 & 1808.04 \\
2023 & 2970.11 & 909.14 \\
2024 & 3203.30 & 457.14 \\
2025 & 3436.53 & 237.16 \\
\hline
\end{tabular}

Then use the statistical value and the predicted value to calculate the unit cost of carbon emission reduction in the ten-year period from 2016 to 2025 according to formula (1), as shown in Table 11:

Table 11. Unit cost of carbon emission reduction.

\begin{tabular}{cc}
\hline Year & $\begin{array}{c}\text { Unit cost of carbon emission reduction } \\
\text { (yuan/kgCO2) }\end{array}$ \\
\hline 2016 & 94.62 \\
2017 & 33.62 \\
2018 & 14.76 \\
2019 & 6.76 \\
2020 & 3.06 \\
2021 & 1.45 \\
2022 & 0.66 \\
2023 & 0.31 \\
2024 & 0.14 \\
2025 & 0.07 \\
\hline
\end{tabular}

The results show that electric vehicles play a positive role in carbon emission reduction. Obviously, the amount of carbon emission reduction is in line with an upward trend by years, while the economic cost of carbon emission reduction is in line with a downward trend by years. As a result, the unit cost of carbon emission reduction is inevitably decreasing, and the effectiveness of the carbon emission reduction cost of electric vehicles is gradually improving.

As a matter of fact, the decline in the economic cost of carbon emission reduction is mainly due to two points. First, with the rapid development of electric vehicle technology, especially battery technology, the price gap between electric vehicles and fuel vehicles of the same configuration level is shrinking significantly, which has a decisive impact on the reduction of the economic cost. Second, the current fuel vehicle technology is relatively mature, so the development speed of electric vehicle technology is faster than the optimization of fuel vehicle technology. Then the economy improvement of electric vehicles is greater than the that of fuel vehicles, thus making the fuel cost of electric vehicles more and more lower than fuel vehicles. At the same time, it has also led to an increasing amount of carbon emission reduction.

\section{Conclusion}

This paper does a research on the cost effectiveness of carbon emission reduction of electric vehicles, and analyzes the trend of changes in the benefits of carbon emission reduction based on grey prediction. In order to promote the low-carbon development of the automotive industry and achieve the national carbon emission reduction target, this paper proposes the following suggestions: 1. Vigorously develop electric vehicle related industries, optimize production processes and market environment, reduce electric vehicle 
purchase costs, and promote the application of electric vehicles. 2. Increase investment in the research and development of electric vehicle technology, focus on improving the economy of electric vehicles, and reduce the cost of electric vehicles and the carbon emissions generated during the use stage; 3. Promote the optimization of the energy structure of the power industry, concentrate on the development of clean energy to reduce the carbon emission coefficient of electricity, and then better utilize the energy-saving and emission-reduction advantages of electric vehicles.

Of course, this paper still has certain limitations and deficiencies. For example, in order to ensure that the vehicle models in the research sample only have differences in power systems, the independently developed electric vehicles are not selected in the sample. This will bring errors to the estimation of the economic cost of electric vehicles and should be corrected in the future.

\section{References}

1. SHI Xiao-qing, LI Xiao-nuo, YANG Jian-xin. Research on Carbon Reduction Potential of Electric Vehicles for Low-Carbon Transportation and Its Influencing Factors[J], Environment Science, 2013

2. Zhao Fu-quan, Liu Fei-qi, Liu Zong-wei, et.al. Research on Evaluation Index System for Low-carbon Development of China's Automobile Industry[J], China Engineering Science, 2018

3. ZHAO Zi-xian, SHAO Chao-feng, CHEN Jue. Effects of Private Electric Vehicles on Carbon Emission Reduction in China during Full Life Cycle [J], Research of Environmental Sciences, 2021

4. GAO Yin-qiao, Analysis of Energy Saving and Emission Reduction Effects and Development Paths of Household New Energy Electric Vehicles[J], Internal Combustion Engine and Accessories, 2019

5. KONG Wei-zheng, LI Qiong-hui, WANG Xiao-lu, Analysis of Electric Vehicle Energy Conservation and Emission Reduction Based on Full Cycle Energy Utilization Efficiency[J], Electric Power, 2012

6. SUN Han-jie, The Full Life of Electric Vehicles Based on Different Power Generation Components[J], Electric Engineering, 2017

7. QI Xing-da, LI Xian-jun, ZHANG Bo-wen, Cost Effectiveness Analysis of China's Greenhouse Gas Emission Reduction-Taking Battery Electric Vehicles as an Example[J], Technology Economics, 2017

8. LI Kai, The Application Research of Optimized Grey Prediction Models[D], Shanghai University of Finance and Economics, 2020

9. CHEN Qian-qian, The Grey Prediction Model Based on Composition Data and Its Application[D], Jiangnan University, 2020 